\title{
Left ventricular aneurysm an unusual complication after muscular VSD device closure
}

\begin{abstract}
Cardiac ventricular aneurysms are rare in the pediatric population. Left ventricular (LV) aneurysms can be congenital or acquired. The acquired form may be caused by trauma (7\%), transmural myocardial infarction (55\%), infection (5\%), connective tissue disease, and cardiac surgery (33\%). Most commonly LV aneurysms are of idiopathic origin.

Here we report a 2-years-old girl, with multiple muscular Ventricular Septal Defects (VSDs), large atrial septal defect, secondum type (ASDII) and Patent Ductus arteriosus (PDA). Cardiac catheterization at 10 months showed reactive pulmonary hypertension, she underwent pulmonary artery banding and PDA ligation at the age of 11 months, and then three of the muscular VSDs were closed by Amplatzer devices at the age of 17 months. At the age of 22 months another cardiac catheter to close remaining VSDs showed left ventricular (LV) apical aneurysm. The LV aneurysm was successfully resected surgically.
\end{abstract}

Keywords: Left ventricular aneurysm; Muscular ventricular septal defect closure; Catheter intervention

\section{Case Presentation}

Here we present a 2-years-old girl referred to our Center as a case of multiple VSDs, large ASDII and PDA. She underwent cardiac catheterization at 10 months of age to assess the pulmonary pressure and calculate the shunt. Catheter showed reactive pulmonary hypertension, she underwent pulmonary artery banding and PDA ligation at the age of 11 months. Patient was on regular follow up and she went to close three muscular VSDs with Amplatzer muscular devices size $(8 \mathrm{~mm}, 8$ $\mathrm{mm}$ and $6 \mathrm{~mm}$ ) at the age of 17 months. After 5 months from VSDs closure cardiac catheter was performed to assess other VSDs and possibility of catheter closure, left ventricular angiography showed (Figure $1,2)$ large apical ventricular aneurysm measuring $20 \times 25 \mathrm{~mm}$ and has wide neck measuring $12 \mathrm{~mm}[1,2]$.

Selective coronary angiography was almost normal. Right ventriculogram showed two other small VSDs between devices. Patient was started on Aspirin $40 \mathrm{mg}$ once daily. ECG done at that time showed ST segment elevation in anterolateral leads at lead 1, aVL, V5 and V6 [3].

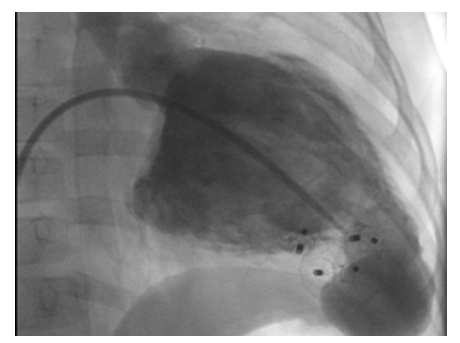

Figure 1: Left ventricle angiogram (RAO) showing VSD devices and large LV apical aneurysm.

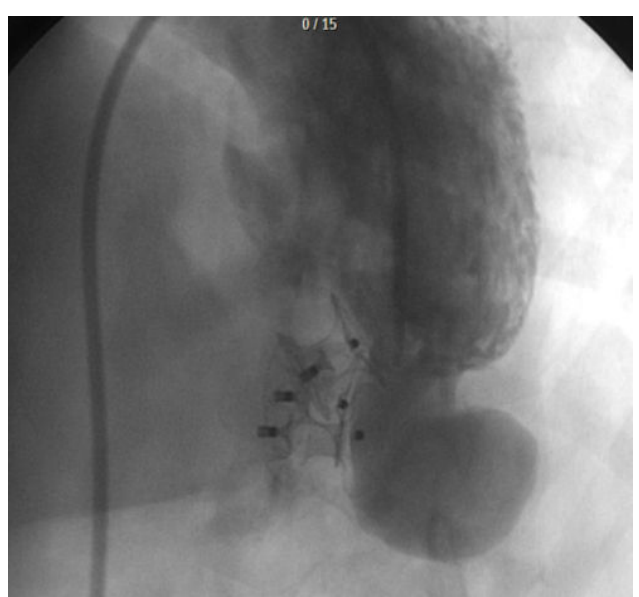

Figure 2: Left ventricle angiogram (LAO with cranial tilt) showing VSD devices and large LV apical aneurysm.
Bashir A. Hawaelrasoul ${ }^{*}$, Atif Al Sahari, Roberto Di Donato, Jassim M Abdulhamed

Department of Pediatric Cardiology, Prince Sultan Cardiac Center (PSCC), Riyadh, KSA

*Author for Correspondence:

Bashir A. Hawaelrasoul

Tel.: 4783000 Ext: 88793

E-mail: hawaelrasoul74@gmail.com

Received date: oct 20, 2018

Accepted date: Jan 17, 2019

Publication date: Jan 25, 2019 
Three dimensional Echocardiography and cardiac MRI (Figure 3) were done which confirmed the diagnosis of the large LV aneurysm with hypokinetic intraventricular septum. The wall of aneurysm seems to be thick and muscular with synchronous movement along the LV wall. Mild to moderately decreased LV

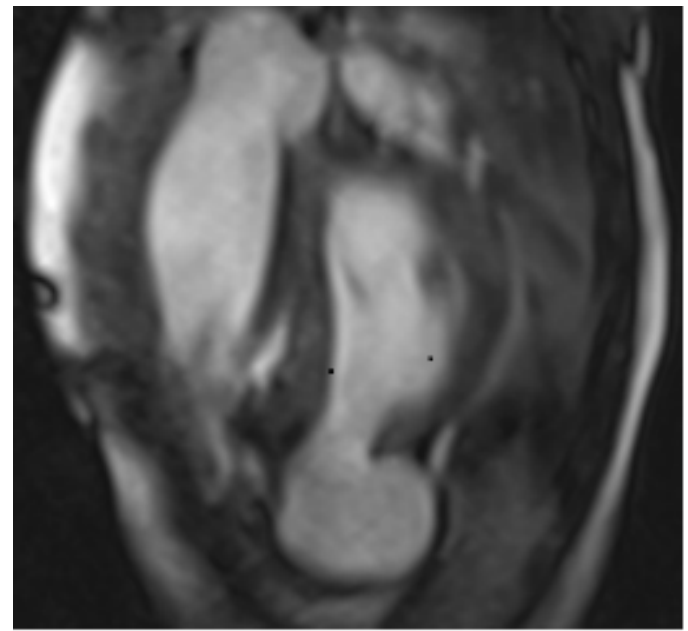

systolic function with ejection fraction (EF) of $40 \%$. Left ventricle aneurysmectomy, ASD closure and PA debanding were surgically performed, the patient made an uneventful recovery and was discharged from the hospital after 7 days, and she was on regular follow up in the clinic and completely a symptomatic.

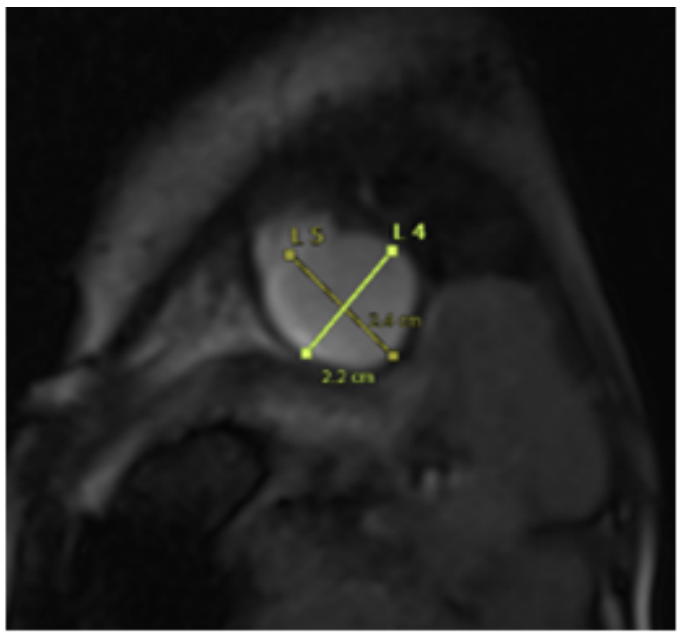

Figure 3: Cardiac magnetic resonance imaging: showing the connection between the left ventricular cavity and the left ventricular apical aneurysm which measures $24 \times 22 \mathrm{~mm}$ (See the figure).

\section{Discussion}

Anatomically ventricular aneurysm also divided into true or false aneurysm. True ventricular aneurysm is a chronic complication of myocardial infarction and usually involves the apical or anterolateral wall $(85 \%)$ and most often follows the left anterior descending coronary artery (LAD) vascular territory (4). A true aneurysmal sac contains endocardium, epicardium, and thinned fibrous scar tissues that are a remnant of the left ventricular muscle. A true aneurysm contained by diseased myocardium can bulge and may be functionally kinetic or dyskinetic. A false or pseudo aneurysm of the left ventricle represents pericardium that contains a ruptured left ventricle A false aneurysm usually involves the inferior and/or posterior ventricular wall. The focal rupture in the myocardial wall creates the neck of the false aneurysm. Because the clinical differentiation between a true aneurysm and a false aneurysm is critical, further evaluation with various imaging modalities is often necessary [4].

In our case it was a true aneurysm proved by 3dimensional echocardiography, cardiac MRI and described by the surgeon intraoperatively.

Development of a true aneurysm is a very rare in pediatric population, but important complication of attempted perventricular VSD closure [5].

The etiology of aneurysm in our case most likely due to myocardial ischemia, but we are not sure if due to coronary thrombus or spasm of the left anterior descending coronary artery during catheter procedure.
The natural history of left ventricular aneurysms in the pediatric population, the mechanism of their formation, and the criteria that place an individual at risk for rupture are unknown [6].

Ventricular aneurysms in the pediatric population are rare and no standardized method of treatment exists. Mostly occur after: Ross/Ross-Konno procedures modified Rastelli-type interventricular tunnels repeated resections of sub aortic stenosis and possibly after: myocardial ischemia trauma drainage of abscess in infective endocarditis progressive herniation of endocardium mostly located: in LV outflow tract [6]. According to our knowledge this is the first case report of LV true aneurysm after VSD device closure.

Cardiac MRI is a non-invasive modality that enables the diagnosis of LV aneurysm. It is useful in identification of the pericardium, detection of thrombi, and in distinguishing between necrotic and normal myocardium [7].

Surgical techniques currently in use for correction of a left ventricular aneurysm are based on reconstruction of the left ventricle or a reduction of its volume with the goal of restoring the normal cardiac geometry [8].

While thrombus formation is common in LV aneurysms, the risk of cerebral embolization is considered to below [9].

\section{Acknowledgement}

The authors would like to thank Dr. Alotay, Abdulmajeed and Dr. Ahmed, Salim from our Imaging department for doing 3-Dimentional 
echocardiography and Cardiac MRI to delineate the aneurysm.

\section{References}

1. Veeragandham RS, Backer CL, Mavroudis C, et al. Traumatic left ventricular aneurysm and tricuspid insufficiency in a child. Ann Thorac Surg. 66:247-8 (1998).

2. Weesner KM, Byrum C, Rosenthal A. Left ventricular aneurysms associated with intraoperative venting of the cardiac apex in children. Am Heart J. 101:622-5 (1981).

3. Grossi EA, Colvin SB, Galloway AC, et al. Repair of posterior left ventricular aneurism in a six year old boy. Ann Thorac Surg.51:484-7 (1991).

4. https://www.vcuthoracicimaging.com/Historyanswer.aspx? qid $=10 \&$ fid $=1$
5. Ozyilmaz I, Saygi M, Yildiz O, et al. Surgical repair of true left ventricular aneurysm in an infant: a rare complication after unsuccessful perventricular VSD closure. World J Pediatr Congenit Heart Surg. 5(4):637-9 (2014).

6. H Chiu, M Gulecyuz, M Ilbawi, et al. Cardiac ventricular aneurysm in a child. Pediatr Cardiol. 22(3):242-244 (2001)

7. Gill S, Rakhit DJ, Ohri SK, et al. Left ventricular true and false aneurysms identified by cardiovascular magnetic resonance. Br J Radiol. 84:e35-e37(2011).

8. Jatene AD. Left ventricular aneurysmectomy: resection or reconstruction. J Thorac Cardiovasc Surg. 89(3): 321-31(1985).

9. Emin Ozdogan M, Levent Oktar G, Tunaoglu S, et al. Post traumatic left ventricular pseudoaneurysm in a child. Thorac Ann. 9:135-137(2001) 